\title{
POSTSYNAPTIC BLOCK OF FROG NEUROMUSCULAR TRANSMISSION BY CONOTOXIN GI
}

\author{
OWEN B. MCMANUS ${ }^{2}$ AND JAMES R. MUSICK
}

Department of Physiology, University of Utah School of Medicine, Salt Lake City, Utah 84108

Received February 7, 1984; Revised June 12, 1984; Accepted August 1, 1984

\begin{abstract}
Conotoxin GI, a peptide neurotoxin contained in the venom of the marine snail Conus geographus, was applied to the cutaneous pectoris muscle of the frog, and the effects on the postsynaptic response to acetylcholine were examined. Conotoxin GI reversibly blocked nerve-evoked mucle contractions at concentrations greater than or equal to 3 to $4 \mu \mathrm{M}$. Micromolar concentrations of conotoxin GI significantly reduced the amplitude of miniature endplate potentials and membrane depolarizations produced by ionophoretic application of acetylcholine, suggesting that the toxin reduced the postsynaptic sensitivity to acetylcholine. The reduction in the sensitivity of the muscle to acetylcholine was not due to changes in muscle fiber resting membrane potential or input resistance. Conotoxin GI reduced the amplitudes but did not affect the rates of decay of focal, extracellularly recorded endplate currents or miniature endplate currents, suggesting that the toxin did not affect the lifetime of ion channels opened by acetylcholine. Miniature endplate currents decay five to six times more slowly than normal when acetylcholinesterase is blocked with neostigmine methyl sulfate due to repeated binding of acetylcholine to receptors as it diffuses from the synaptic cleft. Conotoxin GI reduced the amplitude and increased the rate of decay of miniature endplate currents recorded in the presence of neostigmine methyl sulfate, suggesting that the toxin reduced the binding of acetylcholine to endplate receptors. These results are consistent with the hypothesis that conotoxin GI blocks neuromuscular transmission at the frog endplate by reducing the binding of acetylcholine to receptors.
\end{abstract}

Conus geographus is a marine snail with a well developed venom apparatus that it uses both defensively and in preying on small fish. The crude venom of $C$. geographus is lethal to most vertebrates and causes death by flaccid paralysis and respiratory failure (Endean et al., 1974; Cruz et al., 1978). The crude venom blocks endplate and miniature endplate potentials (MEPPs), and the response of skeletal muscle to acetylcholine $(\mathrm{ACh})$, carbachol, and direct electrical stimulation (Spence et al., 1978; McManus, O. B. and Musick, J. R., unpublished observations). Two toxic peptides (conotoxins GI and GII) contained in the crude venom have been purified and characterized (Cruz et al., 1978; Gray et al., 1981; Luque, 1983). Conotoxins GI and GII are closely related peptides containing 13 amino acid residues each, but differing in three conservative amino acid substitutions. Both peptides are basic, contain two disulfide bonds, and are tightly folded. An equimolar mixture

${ }^{1}$ This work was supported by National Institute of Health Grants NSO7938 and NSO7172 to C. Ezyaguirre and GM22737 to W. R. Gray and B. M. Olivera, and a University of Utah Graduate Research Fellowship. We thank D. Yoshikami for valuable suggestions during the course of these experiments, J. Rivier for providing conotoxin GI, R. Tuckett, K. Horch, and Y. Y. Wei for assistance with computer facilities, D. Yoshikami, C. Eyzaguirre, K. Magleby, and M. Weinstock for comments on the manuscript, and J. Fisher and B. Evans for technical assistance.

${ }^{2}$ Current address: Department of Physiology and Biophysics, University of Miami School of Medicine, P.O. Box 016430, Miami, FL 33101 . of conotoxins GI and GII was shown to block neuromuscular transmission, most likely at a postsynaptic site (McManus et al., 1981). The purpose of this study is to investigate the postsynaptic effects of a pure, synthetic form of conotoxin GI whose amino acid sequence is: Glu-Cys-Cys-Asn-Pro-Ala-CysGly-Arg-His-Tyr-Ser-Cys- $\mathrm{NH}_{2}$ (Gray et al., 1981). Conotoxin $\mathrm{GI}$ is found to block the response of skeletal muscle to acetylcholine, most likely by decreasing the binding of $\mathrm{ACh}$ to its receptor.

\section{Materials and Methods}

Experiments were performed on cutaneous pectoris muscles of Rana pipiens. The bathing solution contained: $107 \mathrm{mM} \mathrm{NaCl} ; 2.5 \mathrm{mM} \mathrm{KCl}$; $2.0 \mathrm{mM} \mathrm{CaCl}_{2} ; 2.5 \mathrm{mM}$ HEPES buffer; $5.5 \mathrm{~mm}$ glucose; the solution was adjusted to $\mathrm{pH} 7.7$ by addition of $\mathrm{NaOH}$, as this value is close to the measured value in frog (Reeves, 1972). The preparation was allowed to remain at room temperature $\left(22^{\circ} \mathrm{C}\right)$. In some experiments, a modified bathing solution was used to reduce the EPP amplitude to a level below that required to initiate muscle action potentials. This modified solution was identical to the above solution except that it contained 0.3 to $0.5 \mathrm{mM} \mathrm{CaCl}_{2}$ and $1.5 \mathrm{mM} \mathrm{MgCl}_{2}$. Conotoxin GI was synthesized and kindly provided by Dr. Jean Rivier of the Salk Institute. The toxin was dissolved in normal bathing solution $(80 \mu \mathrm{M})$ and stored frozen in small aliquots until immediately prior to use. Small volumes (10 to $100 \mu$ l) of this solution were then injected into the bathing solution, and mixed by a small pump that recirculated the solution.

Membrane potentials were recorded from endplate regions of surface muscle fibers with $3 \mathrm{M} \mathrm{KCl-filled} \mathrm{microelectrodes} \mathrm{using} \mathrm{conventional}$ recording techniques and stored on magnetic tape or photographed from the oscilloscope for later analysis. Depolarizations produced by ionophoretic application of ACh and MEPP amplitudes were corrected 
for any small changes in resting membrane potential according to Katz and Thesleff (1957). Depolarizations produced by ionophoretic application of $\mathrm{ACh}$ were kept small to reduce nonlinear summation of potential changes (Martin, 1966). Endplates were located using $\times 400$ magnification. The electrodes used to deliver ionophoretic pulses of ACh were filled with $1 \mathrm{M} \mathrm{ACh}$ chloride and had resistances of 50 to 150 megaohms. These electrodes were positioned 20 to $50 \mu \mathrm{m}$ above the endplate. At this distance, a slight drift in the position of the ionophoretic electrode would not be expected to greatly affect the amplitude or shape of the ionophoretic potential. The resting efflux of ACh from the pipette was retarded by applying a steady braking current ( 2 to $5 \mathrm{nA}$ ), and $\mathrm{ACh}$ was ejected from the pipette by current pulses delivered from a constant current source.

Input resistance was determined by passing 50 - to 100 -msec current pulses through the recording electrode using an active bridge circuit, and measuring the resultant membrane potential changes. In a few experiments, current was injected through a second intracellular electrode positioned within $50 \mu \mathrm{m}$ of the recording electrode, and the results were similar to those obtained using the bridge circuit. Current pulses were in a range that produced linear current-voltage relations and were sufficiently long to allow the potential change to reach steady state.

Extracellular end plate currents (EPCs) and miniature endplate currents (MEPCs) were recorded using the focal extracellular recording technique (Katz and Miledi, 1972, 1973). The microelectrodes were filled with $0.5 \mathrm{M} \mathrm{NaCl}$, had resistances of 30 to 60 megaohms, and responded to a square current pulse with a time constant of $0.15 \mathrm{msec}$. 'The signals were stored on FM magnetic tape (bandwidth, DC-10 kHz). Groups of 10 to 50 EPCs or MEPCs were digitized at a typical rate of 50 sample points/msec, stored, and averaged on a microcomputer. Averaging was triggered by a current pulse delivered a fixed interval before the EPC or by the rising phase of the MEPC.

\section{Results}

Conotoxin GI blocks nerve-evoked muscle contractions. Conotoxin GI (3 to $4 \mu \mathrm{M}$ ) blocked nerve-evoked contractions of the frog cutaneous pectoris muscle. This was determined by stimulating the nerve supramaximally while steadily increasing the toxin concentration in the bath until muscle contractions ceased. Paralysis was reversed after a washout of $10 \mathrm{~min}$ or less. Under similar conditions, curare blocked nerve-evoked muscle contractions at $6 \mu \mathrm{M}$. Conotoxin GI is thus slightly more potent than curare in blocking neuromuscular transmission in frog muscle. In contrast, conotoxin GI was roughly 10 times more potent than curare in blockage of nerve-evoked contractions of the mouse diaphragm. Conotoxin GI blocked mouse diaphragm contractions at 0.2 to $0.4 \mu \mathrm{M}$, while approximately $2 \mu \mathrm{M}$ curare was required (McManus et al., 1981). Thus, the frog neuromuscular junction was more resistant to block by both conotoxin GI and curare than the mouse neuromuscular junction, but this resistance was greater for conotoxin GI.

Conotoxin GI reduces the amplitude of ionophoretic potentials and miniature endplate potentials. The effect of conotoxin GI on depolarizations produced by ionophoretic application of ACh is shown in Figure 1. An ionophoretic potential and the current through the ionophoretic electrode under control conditions are shown in $A$. $B$ shows an ionophoretic potential from the same cell 15 min after injection of conotoxin GI into the bath; final toxin concentration was approximately $1 \mu \mathrm{M}$. The amplitude of the ionophoretic potentials was reduced by $64 \%$ from $1.35 \pm 0.02 \mathrm{mV}(n=11$ measurements $)$ in control to $0.48 \pm$ $0.03 \mathrm{mV}(n=5)$ in the presence of toxin. The average elapsed time between the ionophoretic current pulse and the peak of the ionophoretic potential was $0.41 \pm 0.01 \mathrm{sec}$ both in the control and in the presence of toxin. Because the time to peak of an ionophoretic potential is related to the distance between the ionophoretic electrode and the endplate (Del Castillo and Katz, 1955; Dreyer and Pepper, 1974), the similar rise times suggest that the position of the ionophoretic electrode was stable. MEPPs were recorded together with the ionophoretic potentials. Their amplitude was reduced by $29 \%$ from $0.45 \pm$
A

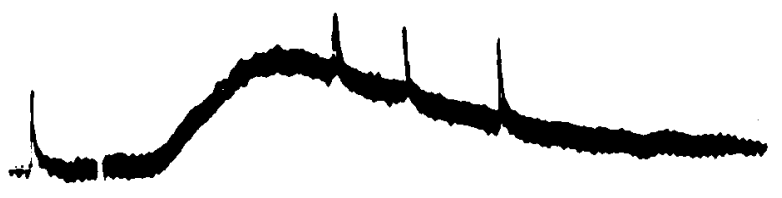

1

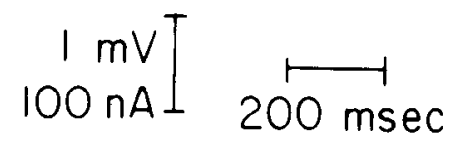

8

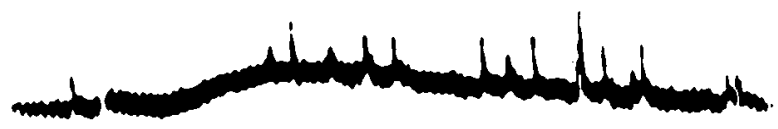

4

Figure 1. Effects of conotoxin GI on ionophoretic potentials. Upper traces of each pair show membrane depolarization resulting from ionophoretic application of ACh. Spontaneously occurring MEPPs are also seen. Lower traces of each pair show current through ionophoretic electrode. $A$ shows ionophoretic potential and MEPPs without toxin; $B$ was 15 min after adding $0.64 \mathrm{nmol}$ of conotoxin GI to the bath (toxin concentraion, approximately $0.9 \mu \mathrm{M}$ ). Resting membrane potential was $-89 \mathrm{mV}$ in $A,-86 \mathrm{mV}$ in $B$.

$0.02 \mathrm{mV}(n=61)$ in control to $0.32 \pm 0.01 \mathrm{mV}(n=90)$ in the presence of toxin. Similar effects were observed in seven other experiments. These results suggest that conotoxin GI has a postsynaptic effect at the frog endplate.

An increase in the frequence of MEPPs in the presence of conotoxin GI can be seen in Fig. $1 B$. This effect was often, though not always, observed after exposure to conotoxin GI, despite a substantial reduction in MEPP amplitude.

Ionophoretic potentials were reduced to a greater degree than were MEPPs in the experiment shown in Fig. 1. This would not be expected if the amplitude of both ionophoretic potentials and MEPPs were simply related to the number of free $\mathrm{ACh}$ receptors. The reductions in the amplitudes of MEPPs are plotted against the reductions in amplitudes of the ionophoretic potentials and the results are shown in Figure 2. Each point is the average of 5 to 15 ionophoretic potentials and 10 to 250 MEPPs from six experiments in which 10 levels of block were obtained. The amplitudes of the MEPPs ranged from 0.5 to 1.5 $\mathrm{mV}$ and the ionophoretic potentials ranged from 1 to $4 \mathrm{mV}$ in control. The solid line was fit to the data by least squares regression. The dashed line represents an equal block of MEPPs and ionophoretic potentials. The experimental measurements clearly do not fit this relation. Some factors that could account for this difference are considered in "Discussion."

Effects on muscle fiber input resistance. Conotoxin GI caused a significant reduction in the amplitude of MEPPs and iono- 


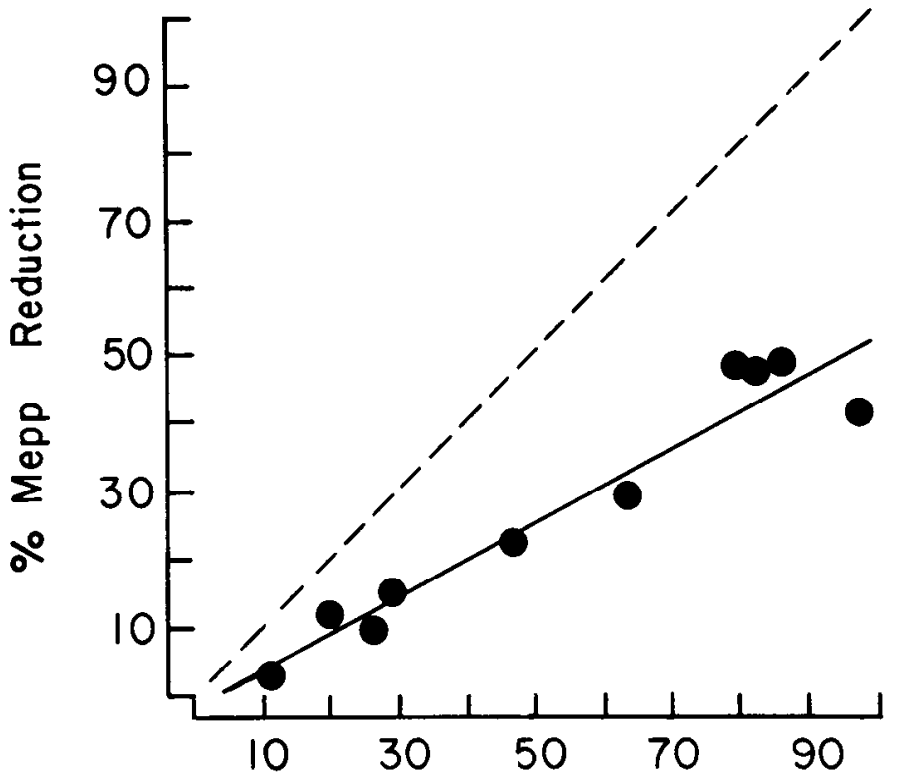

$\%$ Ionophoretic Potential Reduction

Figure 2. Reductions of MEPP and ionophoretic potential amplitudes by conotoxin GI. Data are from six experiments at 10 levels of block by toxin. The solid line was fitted to data by regression analysis and the dashed line represents equal reduction of ionophoretic potential and MEPP amplitudes.

phoretic potentials (Figs. 1 and 2). These effects might be secondary to a reduction in muscle fiber input resistance caused by the toxin. To test this possibility, the input resistance of individual muscle fibers was measured in the absence and presence of conotoxin GI.

Figure 3 shows the effects of conotoxin GI on input resistance and MEPP amplitude recorded in the same muscle fiber. $A_{1}$ and $A_{2}$ show membrane depolarization caused by injection of 1 $\mathrm{nA}$ of current and MEPPs recorded in the absence of toxin, respectively. $B_{1}$ and $B_{2}$ show similar recordings $10 \mathrm{~min}$ after applying sufficient toxin to block nerve-evoked muscle contractions (approximately $4 \mu \mathrm{M}$ ). The amplitude and time course of the electrotonic potential recorded in the presence of conotoxin GI are identical to control, while the MEPP amplitude is reduced by $37 \%$ in the presence of toxin. In eight experiments of this type, the average input resistance in control was $1.64 \pm$ 0.34 megaohms, while in the presence of conotoxin GI it was $1.62 \pm 0.32$ megaohms. These results suggest that the reduction in MEPP amplitudes by micromolar concentrations of conotoxin GI was not due to changes in muscle fiber input resistance.

Conotoxin GI reduces the amplitude with little effect on rate of decay of MEPCs and EPCs. These experiments examined whether conotoxin GI blocks the response to ACh at the frog endplate by reducing the effective lifetime of ion channels opened by ACh. The rate of decay of focal MEPCs and EPCs was measured in normal bathing solution and in the presence of conotoxin GI, while recording from the same location. EPCs and MEPCs decay according to a single exponential time course with a slope that represents the effective rate of closing of ion channels opened by ACh (Magleby and Stevens, 1972; Anderson and Stevens, 1973; and see Colquhoun and Sakmann, 1981). If the toxin changes the effective open time of Ach ion channels, then the rate of decay of the EPCs and MEPCs should reflect this change.

Figure 4 shows the effect of conotoxin GI on focal extracellular MEPCs. Signals are shown while recording in normal bathing solution $(A)$, after $7 \mathrm{~min}$ in the presence of approximately $1.2 \mu \mathrm{M}$ conotoxin $\mathrm{GI}(B)$, and $15 \mathrm{~min}$ after washout of the toxin $(C)$. Figure $5 A$ shows superimposed averages of MEPCs from the same experiment before, during (smallest signal), and after (largest signal) exposure to toxin. The amplitudes and time courses of the averaged signals are similar to the individual signals while the noise is reduced. These signals show that conotoxin GI caused a reversible reduction in the amplitude of MEPCs (34\%) with little apparent effect on rate of decay of MEPCs. The change in the amplitude of the averaged MEPCs probably underestimates the actual reduction because subthreshold MEPCs are excluded from the averaged signals.

Figure $5 B$ shows the averaged MEPCs from Figure $5 A$ plotted semilogarithmically against time. MEPCs in control and in the presence of toxin decayed as a single exponential with similar slopes. The time constant of decay was $1.38 \mathrm{msec}$ in control and $1.32 \mathrm{msec}$ in the presence of toxin. In five experiments of this type, the toxin decreased MEPC amplitude by $32 \pm 6 \%$ while the time constant of decay was $1.23 \pm 0.09$ msec under control conditions and $1.19 \pm 0.07 \mathrm{msec}$ in the presence of toxin (not significantly different). Similarly, conotoxin GI reduced the amplitudes, but had little effect of the rates of decay of endplate currents (data now shown). In separate experiments, procaine $\left(10^{-5} \mathrm{gm} / \mathrm{ml}\right)$ was found to reduce the rate of decay of EPCs and MEPCs indicating that changes in the rate of decay would have been observed in the averaged data. These results suggest that concentrations of conotoxin GI that significantly reduced the amplitudes of EPCs and MEPCs had no apparent effect on their rates of decay.

Conotoxin GI reduces the amplitude and time constant of decay of $M E P C s$ recorded with AChE blocked. When acetylcholinesterase (AChE) is inhibited, the decay of endplate currents is prolonged (Takeuchi and Takeuchi, 1959; Kordas, 1969, 1977; Magleby and Stevens, 1972; Katz and Miledi, 1973; Magleby and Terrar, 1975). In this case, the rate of EPC decay does not directly reflect the effective rate of closing of ion channels opened by $\mathrm{ACh}$, but is governed by the rate of delayed diffusion of $\mathrm{ACh}$ out of the snyaptic cleft (Katz and Miledi, 1973). The delayed diffusion of $\mathrm{ACh}$ out of the synaptic cleft in the presence of an anticholinesterase results from repeated binding of $\mathrm{ACh}$ to receptors along the diffusion path; drugs that reduce binding of $\mathrm{ACh}$ to receptors increase the rate of diffusion of $\mathrm{ACh}$ from the snyaptic cleft, and thus increase the rate of decay of the prolonged endplate currents in the presence of an anticholinesterace (Katz and Miledi, 1973; Magleby and Terrar, 1975; Colquhoun et al., 1977; Kordas, 1977). If conotoxin GI reduces binding of $\mathrm{ACh}$ to its receptor, then conotoxin GI should also speed up the decay of endplate currents prolonged by an anticholinesterase. The following section tests this possibility.

Figure 6 shows that conotoxin GI reversibly reduced both the amplitude and time constant of decay of MEPCs recorded in the presence of $3 \mu \mathrm{M}$ neostigmine methyl sulfate. This concentration of neostigmine has no measurable effect on channel lifetime in this preparation (Katz and Miledi, 1973). Computer averages of 10 to $15 \mathrm{MEPCs}$ from control conditions, 5 min after exposure to approximately $1 \mu \mathrm{M}$ conotoxin GI (smaller signal), and $30 \mathrm{~min}$ after washout of the toxin are shown in Figure $6 A$. The control and washout signals superimpose, but in the presence of conotoxin GI, the MEPC amplitude was reduced by one-third and the rate of decay was increased by just over one-third. This reduction in MEPC amplitude is similar to the reduction in amplitude caused by the toxin in the absence of neostigmine. The averaged MEPCs are plotted semilogarithmically against time in Figure $6 B$. The control MEPC was fit by an exponential with a time constant of $6.41 \mathrm{msec}(-)$. In the presence of toxin, the time constant of 
A
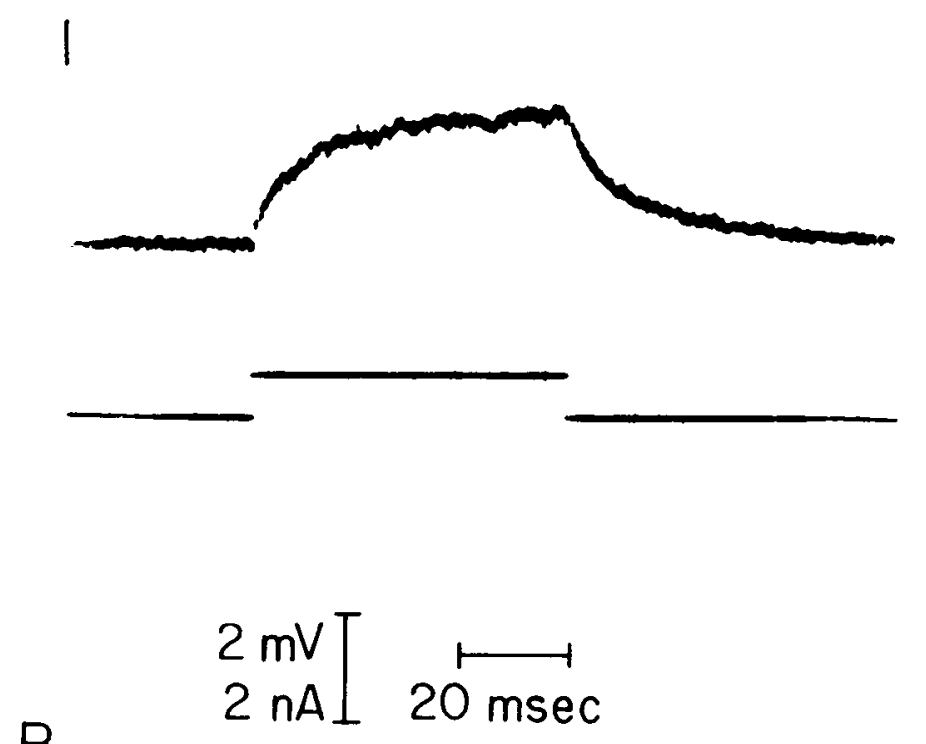

B

1

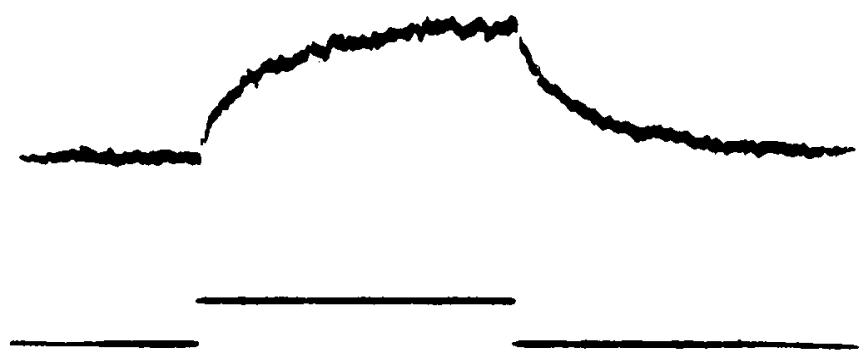

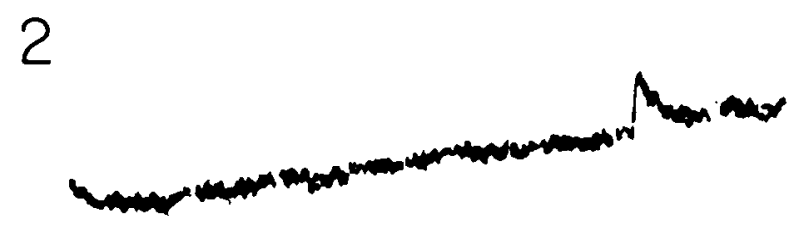
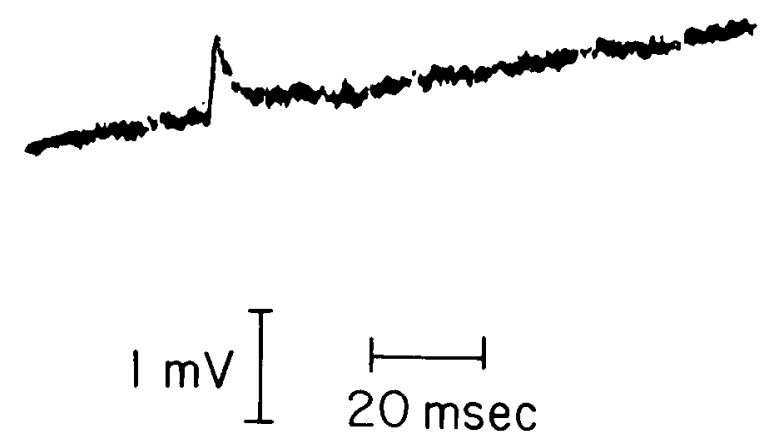

2

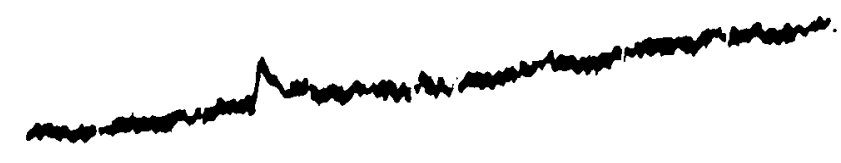

Figure 3. Response to injected current $\left(A_{1}\right)$ and MEPPs $\left(A_{2}\right)$ without toxin are compared to response to injected current $\left(B_{1}\right)$ and MEPPs $\left(B_{2}\right)$ recorded after 10-min exposure to approximately $4 \mu \mathrm{M}$ conotoxin GI. Input resistance of this muscle fiber was $2.33 \pm 0.04$ megaohms without toxin and $2.36 \pm 0.04$ megaohms in the presence of toxin. MEPP amplitude was reduced from $0.47 \pm 0.02$ to $0.30 \pm 0.02 \mathrm{mV}$ by the toxin. Resting membrane potential was $-88 \mathrm{mV}$ in $A$ and $-83 \mathrm{mV}$ in $B$.

decay was reduced to $3.89 \mathrm{msec}(\mathrm{O})$. After washout of toxin, the time constant of decay returned to $6.50 \mathrm{msec}(\mathbf{O})$. In this experiment, conotoxin GI caused a $39 \%$ decrease in the time constant of decay and a $34 \%$ decrease in the amplitude of MEPCs.

Figure 7 shows averaged MEPCs recorded in $6 \mu \mathrm{M}$ neostigmine at different levels of block by conotoxin GI. Control signals are shown as the largest averaged signal in $7 A$ and as the filled circles plotted semilogarithmically against time in $7 B$. The control time constant of decay was $5.83 \mathrm{msec}$. To illustrate the dose dependence of these effects, MEPCs are shown in the presence of two different concentrations of conotoxin GI. At the lower concentration, MEPC amplitude was reduced by $42 \%$ and the time constant of decay was reduced by $32 \%(0)$. At the higher concentration, the amplitude was reduced by $54 \%$ and the time constant of decay was reduced by $40 \%$ (O). These results suggest that the amplitude and time constant of decay of MEPCs recorded in the presence of neostigmine are reduced by increasing concentrations of conotoxin GI.

In seven experiments done in the presence of an anticholinesterase, conotoxin GI consistently reduced both the amplitude and time constant of decay of MEPCs. The average reduction in amplitude was $26 \pm 7 \%$. The average time constant of decay declined by $36 \pm 3 \%$ ( $p<0.005$ compared to control).

When AChE was blocked by the irreversible inhibitor methane sulfonyl fluoride (Kitz and Wilson, 1963; Kordas, 1977) or by a 10 -fold excess of neostigmine, conotoxin GI similarly decreased the amplitude and time constant of decay of MEPCs (data not shown). The effects of the toxin are thus not due to a reversal of the $\mathrm{AChE}$ block.

Figures $6 B$ and $7 B$ show that MEPCs recorded in the presence of neostigmine decay approximately exponentially, but this rate is slower soon after the peak. This small difference was consistently seen in eight experiments and was also seen in the decay of EPCs recorded by Magleby and Terrar (1975), which they attributed to a positive cooperative effect between binding sites for ACh. Near the peak of the EPC the concentration of $\mathrm{ACh}$ in the cleft and the apparent binding affinity will be higher, so as a result, the rate of diffusion of $\mathrm{ACh}$ will be slower.

Katz and Miledi (1973) suggested that the fraction of ACh bound during a MEPC recorded in the presence of an anticholinesterase can be calculated by: $\left.p=\left(\tau_{\text {con }}-\tau_{\text {tox }}\right) / \tau_{\text {con }}-\alpha \tau_{\text {tox }}\right)$ where $\tau_{\text {con }}$ is the time constant of decay seen in control, $\tau_{\text {tox }}$ is the time constant in toxin, and $\alpha$ is the ratio of toxin to control amplitudes. In five experiments using conotoxin GI, $p=0.67$ \pm 0.05 . This is similar to the $p$ value of 0.66 found by Katz and Miledi (1973) using both curare and $\alpha$-bungarotoxin, suggesting a similarity in the effects of conotoxin GI, curare, and $\alpha$ bungarotoxin on the $\mathrm{ACh}$ receptor. 
A
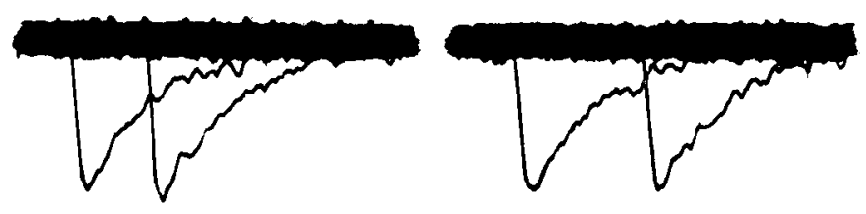

B
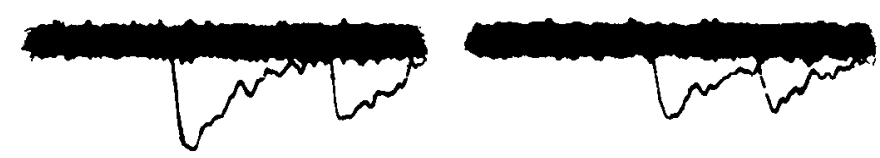

C
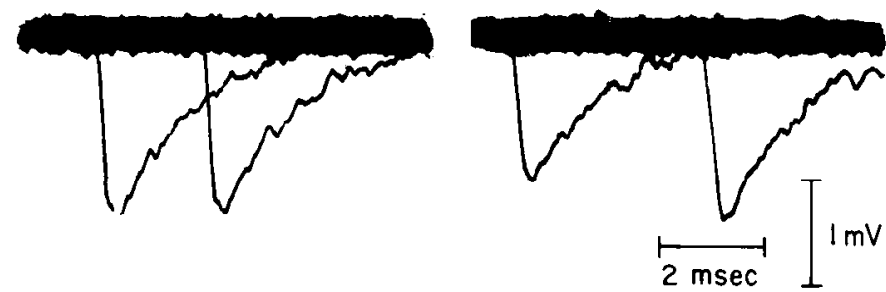

Figure 4. A, extracellular MEPCs without toxin; $B$, after 7-min exposure to approximately $1.2 \mu \mathrm{M}$ conotoxin GI; $C$, after 20 -min washout of toxin. Amplitude is reduced in presence of toxin while shape is not changed. The thick base line is due to superimposed repeated sweeps.

\section{Discussion}

An earlier study (McManus et al., 1981) suggested that a mixture of conotoxins GI and GII blocked neuromuscular transmission, most likely at a postsynaptic site. The purpose of the present study was to examine the effects of conotoxin GI on the postsynaptic response to $\mathrm{ACh}$ at the frog endplate.

The amplitudes of both ionophoretic potentials and MEPPs were reduced by conotoxin GI, suggesting that the toxin reduced the sensitivity of the postsynaptic membrane to $\mathrm{ACh}$. This reduction in sensitivity was not due to changes in muscle fibre resting membrane potential or input resistance.

If the toxin reduced the number of free $\mathrm{ACh}$ receptors, the amplitude of ionophoretic potentials might be expected to decrease in proportion to reductions in MEPP amplitude. However, the results in Figure 2 show that ionophoretic potentials were reduced to a greater degree than were MEPPs. Similar observations were made by Pennefather and Quastel (1981) while blocking Ach receptors with curare. They could explain their results by assuming that, when some of the receptors are blocked by a competitive antagonist, the fraction of ionophoretically applied ACh that is bound to receptors is reduced in proportion to the fraction of the blocked receptors. However, neurally released $\mathrm{ACh}$ simply diffuses further before binding to receptors, and the fraction of $\mathrm{ACh}$ that is bound to receptors is not changed to the degree expected. Several other factors could contribute to the greater block of ionophoretic potentials than MEPPs seen with conotoxin GI. (1) Ionophoretically applied ACh may preferentially bind to receptors in the outer parts of the synaptic cleft and extrajunctional areas. ACh released from nerve terminals would have access to receptors deeper in the cleft. If the access of the toxin to receptors deep in the cleft
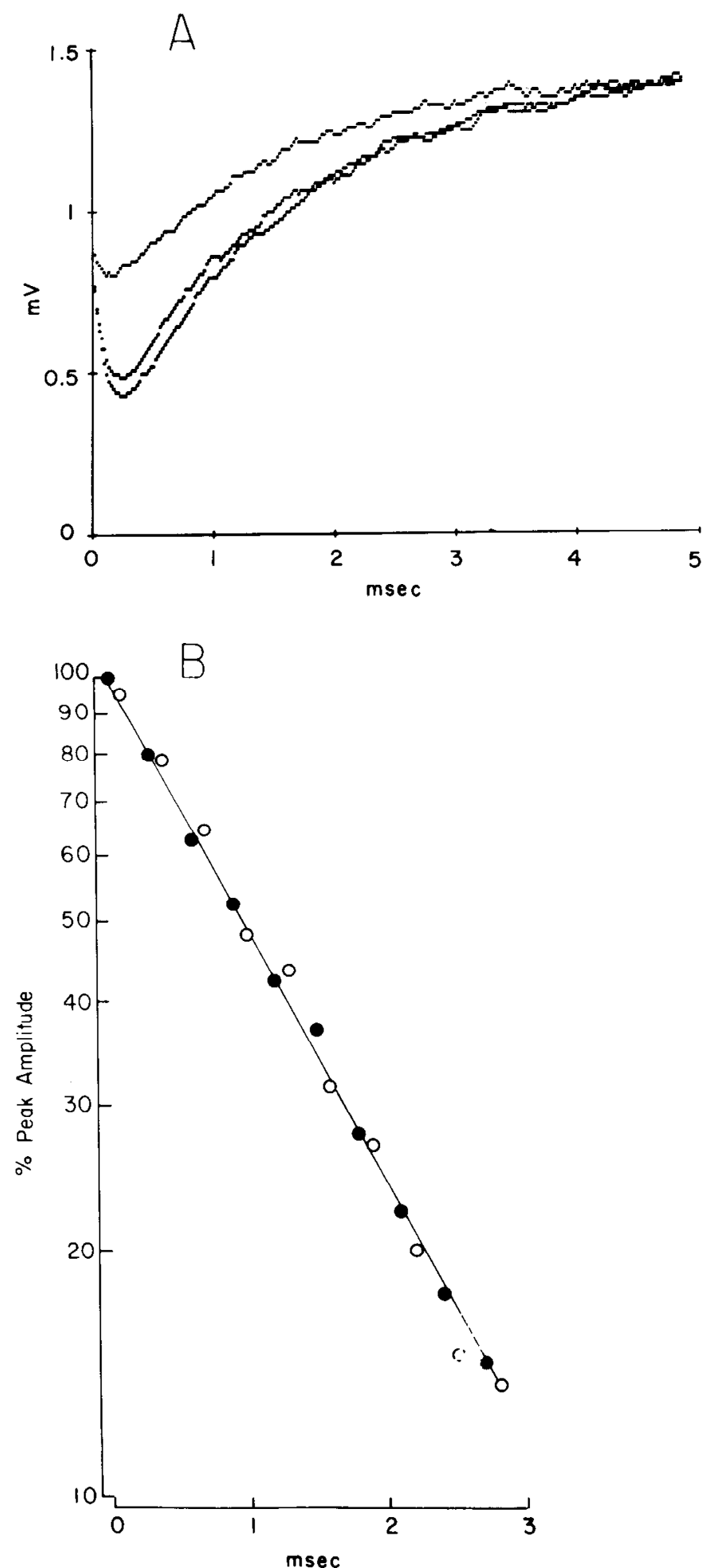

Figure 5. Effects of conotoxin GI on amplitude and rate of decay of extracellular MEPCs. $A$ shows averages of 10 to 15 MEPCs from the experiment shown in Figure 4 without toxin, after 7 -min exposure to approximately $1.2 \mu \mathrm{M}$ toxin (smallest signal), and after 20 -min washout (largest signal). $B$ shows decay of same MEPCs in the absence (O) and presence $(O)$ of toxin plotted semilogarithmically as fraction of peak value against time. Time constant of decay: $1.38 \mathrm{msec}$ in control; 1.32 msec in toxin; $1.26 \mathrm{msec}$ in washout.

were restricted, then MEPPs would be less affected by the toxin than ionophoretic potentials. (2) The population of receptors activated by ionophoretic application of ACh may be pharmacologically different, and thus may have a different sensitivity 

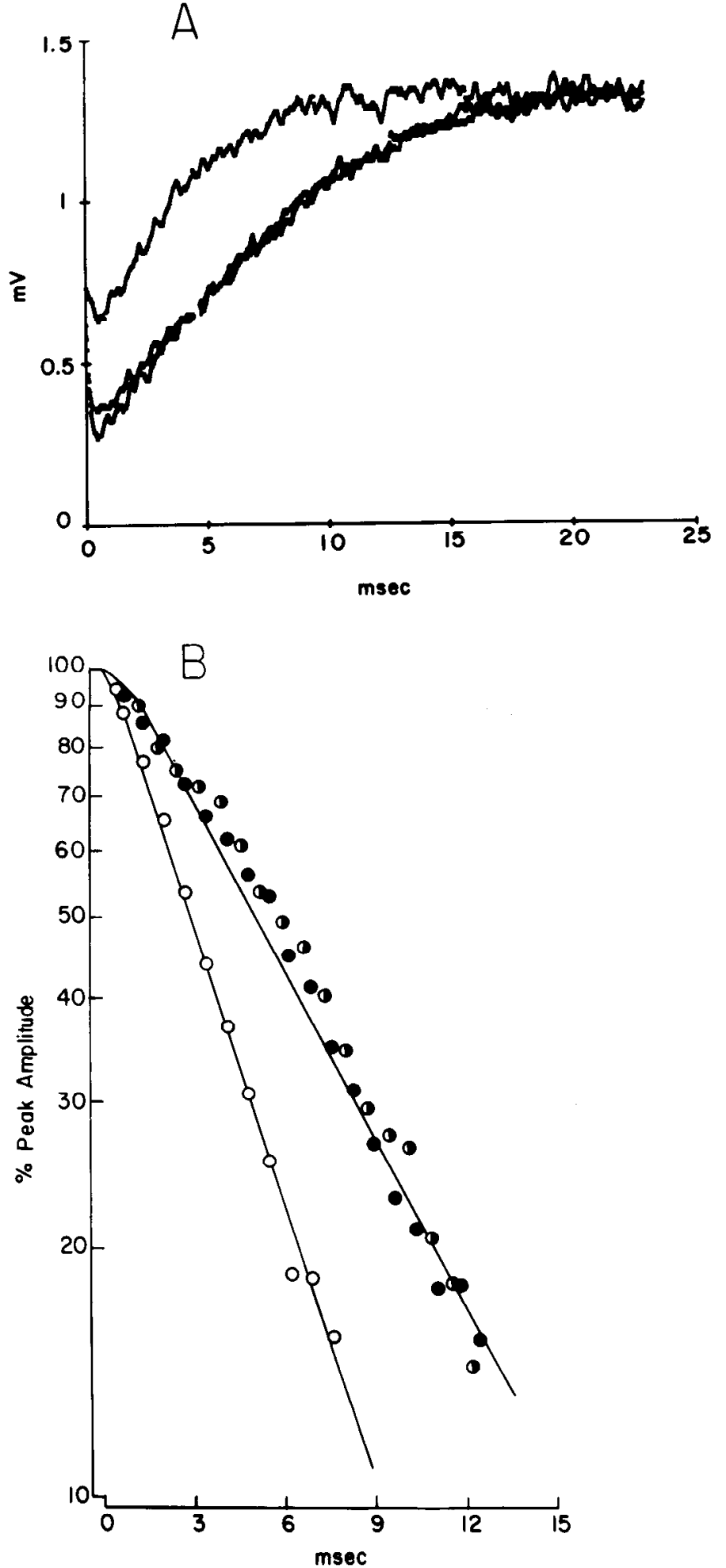

Figure 6. Extracellular MEPCs were recorded with AChE blocked by neostigmine $(3 \mu \mathrm{M})$ with and without conotoxin GI. $A$ shows averages of 10 to 15 MEPCs recorded without toxin, after 5-min exposure to approximately $1 \mu \mathrm{M}$ toxin (smaller signal), and after 30-min washout. $B$ shows decay of same MEPCs recorded without toxin (Q), in the presence of toxin $(O)$, and after washout $(O)$ plotted semilogarithmically against time. Time constant of decay: $6.41 \mathrm{msec}$ in control; 3.89 msec in toxin; and $6.50 \mathrm{msec}$ after washout.
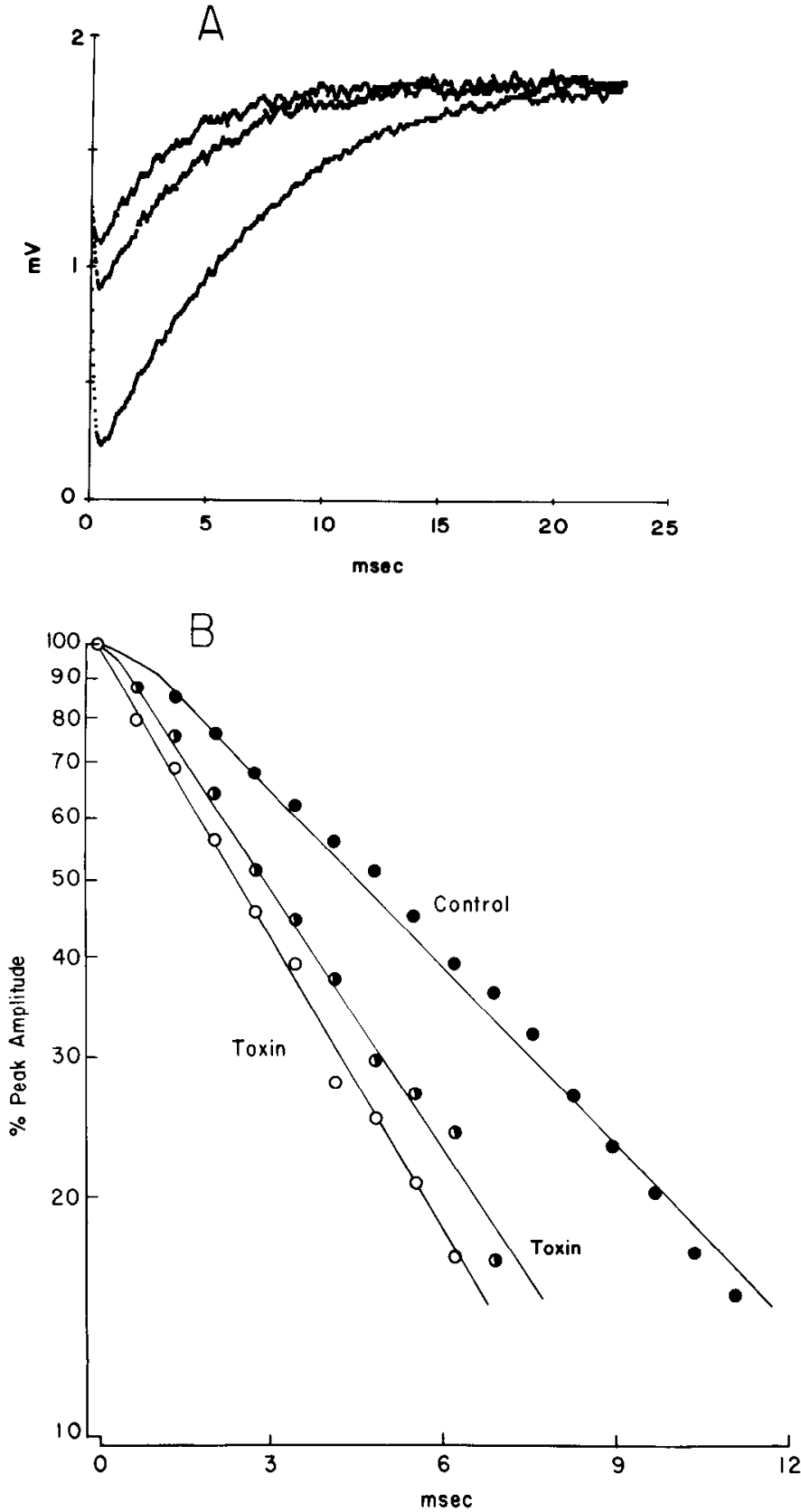

Figure 7. Extracellular MEPCs were recorded in the presence of 6 $\mu \mathrm{M}$ neostigmine at varying levels of block by conotoxin GI. $A$ shows averages of 8 to $20 \mathrm{MEPCs}$ recorded without toxin (largest signal), 2 min (smallest signal), and 5 min after injecting $2.30 \mathrm{nmol}$ of conotoxin GI into the bath and then gradually diluting the toxin by mixing and washout. $B$ shows decay of same MEPCs without toxin (O), and 2 min $(O)$ and $5 \mathrm{~min}(\mathrm{O})$ after adding toxin. Time constant of decay: 5.83 msec in control; $3.47 \mathrm{msec}$ (amplitude reduced by $54 \%$ ) after $2 \mathrm{~min}$; $3.98 \mathrm{msec}$ (amplitude reduced by $42 \%$ ) after $5 \mathrm{~min}$.

to block by conotoxin GI than receptors activated during MEPPs (Albuquerque et al., 1979). (3) If conotoxin GI selectively blocked ACh receptors in the open or desensitized states, then ionophoretic potentials would be reduced more than MEPPs as more channels were opened during ionophoretic potentials than during the shorter MEPPs. No evidence of open channel block by the toxin was seen during the time course of EPCs and MEPCs. The possibility of a slower rate of open channel block was investigated in experiments where a series of ionophoretic potentials was delivered with interpulse intervals of 200 to $1000 \mathrm{msec}$. Ionophoretic potentials occurring 
later in the series would be reduced by toxin to a greater degree than the first pulse if conotoxin GI slowly blocked receptors in the open state. No significant evidence of a use-dependent block of ionophoretic potentials by conotoxin GI was observed (unpublished observations).

The decay rates of focal extracellular EPCs and MEPCs were used to measure the effects of conotoxin GI on the effective lifetimes of ion channels opened by ACh. Concentrations of conotoxin GI that significantly reduced the amplitude of EPCs and MEPCs had no significant effect on their rates of decay. These results suggest that conotoxin GI reduces the response of the frog endplate to $\mathrm{ACh}$ by a mechanism that does not involve a change in the effective lifetime of ion channels opened by $\mathrm{ACh}$.

When AChE is inhibited, the decay of MEPCs is prolonged due to repeated binding of $\mathrm{ACh}$ to receptors as it diffuses from the snyaptic cleft (Katz and Miledi, 1973). Drugs that inhibit binding of $\mathrm{ACh}$, such as curare and $\alpha$-bungarotoxin, increase the rate of decay of the prolonged MEPCs when the AChE is inhibited, as the diffusion of ACh out of the snyaptic cleft is no longer delayed by repeated binding to receptors (Katz and Miledi, 1973; Magleby and Terrar, 1975; Colquhoun et al., 1977). We found that conotoxin GI also increases the rate of decay of the prolonged MEPCs when AChE is inhibited. Since conotoxin GI has no apparent effect on channel lifetime, then the increased rate of decay of the prolonged MEPCs by conotoxin GI when AChE is inhibited most likely results because conotoxin GI reduces the binding of $\mathrm{ACh}$ to its receptor. This conclusion that conotoxin GI blocks binding of $\mathrm{ACh}$ by receptors is supported by an earlier finding that conotoxins GI and GII block the binding of $\alpha$-bungarotoxin to muscle endplate regions (McManus et al., 1981).

At the molecular level, a reduced binding of $\mathrm{ACh}$ to its receptor in the presence of conotoxin GI could arise in two ways. (a) Conotoxin GI could bind to the receptor and thus prevent $\mathrm{ACh}$ from binding by directly blocking the binding site for $\mathrm{ACh}$ or by binding to a nearby site and altering the affinity of ACh for its site. (b) Conotoxin GI could bind to the receptor at a site other than the ACh-binding site and prevent the channel from opening. The three-state kinetic model for the $\mathrm{ACh}$ receptor proposes a binding reaction with $\mathrm{ACh}$ and a subsequent isomerization leading to channel opening (Del Castillo and Katz, 1957; Magleby and Stevens, 1972). If conotoxin GI blocked the opening of ion channels by acting at a site other than the ACh-binding site, then ACh could still bind to the receptor, but the length of time it remained bound would be reduced, as its unbinding would no longer be delayed by channel opening. In this case, the apparent affinity of the receptor for ACh would be reduced by the toxin.

In summary, conotoxin GI reduces the sensitivity of the frog endplate to $\mathrm{ACh}$. This effect is not due to changes in the passive electrical properties of the membrane or to changes in the resting membrane potential. The effects can be best explained by a model in which the toxin binds to the ACh receptor and reduces the binding of $\mathrm{ACh}$.

\section{References}

Albuquerque, E. X., P. W. Gage, and A. C. Oliveira (1979) Differential effect of perhydrohistrionicotoxin on "intrinsic" and "extrinsic" endplate responses. J. Physiol. 297: 423-442.
Anderson, C. R., and C. F. Stevens (1973) Voltage clamp analysis of acetylcholine produced end-plate current fluctuations at frog neuromuscular junction. J. Physiol. 235: 655-691.

Colquhoun, D., and B. Sakmann (1981) Fluctuations in the microsecond time range of the current through single acetylcholine receptor ion channels. Nature 294: 464-466.

Colquhoun, D., W. A. Large, and H. P. Rang (1977) An analysis of the action of a false transmitter at the neuromuscular junction. J. Physiol. 266: 361-395.

Cruz, L. J., W. R. Gray, and B. M. Olivera (1978) Purification and properties of a myotoxin from Conus geographus venom. Arch. Biochem. Biophys. 190: 539-548.

Del Castillo, J., and B. Katz (1955) On the localization of acetylcholine receptors. J. Physiol. 128: 157-181.

Del Castillo, J., and B. Katz (1957) Interaction at endplate receptors between different choline derivatives. Proc. R. Soc. Lond. Biol. 146: 339-356.

Dreyer, F., and K. Peper (1974) Ionotophoretic application of acetylcholine: advantages of high resistance micropipettes in connection with an electronic current pump. Pflugers Arch. 348: 263-272.

Endean, R., G. Parish, and P. Gyr (1974) Pharmacology of the venom of Conus geographus. Toxicon 12: 131-138.

Gray, W. R., A. Luque, B. Olivera, J. Barrett, and L. J. Cruz (1981) Peptide toxins from Conus geographus venom. J. Biol. Chem. 256: 4734-4740.

Katz, B., and R. Miledi (1972) The statistical nature of the acetylcholine potential and its molecular components. J. Physiol. 224: 665699.

Katz, B., and R. Miledi (1973) The binding of acetylcholine to receptors and its removal from the synaptic cleft. J. Physiol. 231: 549-574.

Katz, B., and S. Thesleff (1957) On the factors which determine the amplitude of the miniature endplate potential. J. Physiol. 137: 267278.

Kitz, R., and I. B. Wilson (1963) Acceleration of the rate of reaction of methane sulfonylfluoride and acetylcholinesterase by substituted ammonium ions. J. Biol. Chem. 238: 745-748.

Kordas, M. (1969) The effects of membrane polarization on the time course of the end-plate current in frog sartorius muscle. J. Physiol. 204: 493-502.

Kordas, M. (1977) On the role of junctional cholinesterase in determining the time course of the endplate current. J. Physiol. 270: 133-150.

Luque, F. A. (1983) Peptide toxins from Conus geographus. Ph.D. dissertation, University of Utah.

Magleby, K. L., and C. F. Stevens (1972) A quantitative description of end-plate currents. J. Physiol. 223: 173-197.

Magleby, K. L. and D. A. Terrar (1975) Factors affecting the time course of decay of endplate currents: a possible cooperative action of acetylcholine on receptors at the frog neuromusuclar junction. J. Physiol. 244: 467-495.

Martin, A. R. (1966) Quantal nature of synaptic transmission. Physiol. Rev. 46: 51-66.

McManus, O., J. Musick, and C. Gonzalez (1981) Peptides isolated from the venon of Conus geographus block neuromuscular transmission. Neurosci. Lett. 24: 57-62.

Pennefather, P., and D. M. J. Quastel (1981) relation between subsynaptic receptor blockade and response to quantal transmitter at the mouse neuromuscular junction. J. Gen. Physiol. 78: 313-344.

Reeves, K. B. (1972) An imidazole alphastat hypothesis for vertebrate acid-base regulation: tissue carbon dioxide content and body temperature in bullfrogs. Respir. Physiol. 14: 219-236.

Spence, I., D. Gillessin, R. P. Gregson, and R. J. Quinn (1978) Characterization of the neurotoxic constituents of Conus geographus $(\mathrm{L})$ venom. Life Sci. 21: 1759-1770.

Takeuchi, A., and N. Takeuchi (1959) Active phase of frog's end-plate potential. J. Neurophysiol. 22: 395-411. 